\title{
Morphological Variation in the Seahorse Vertebral System
}

\author{
Variaciones Morfológicas en el Sistema Vertebral del Caballo de Mar
}

"Emilano Bruner \& **Valerio Bartolino

BRUNER, E. \& BARTOLINO, V. Morphological variation in the seahorse vertebral system. Int. J. Morphol., 26(2):247-262, 2008.

SUMMARY: The vertebral system in Hippocampus hippocampus is highly specialised because of the vertical locomotion and tail prehensility. The vertebral elements represent a special case of morphological changes, being the metameric structures organised along a natural functional series. We investigated the shape changes along the vertebral spine in $H$. hippocampus through geometric morphometrics, in order to describe functional and structural patterns. Actually, the dorso-ventral tail bending ability in the genus Hippocampus is one of the most impressive morphological modifications in the evolutionary history of fishes. Vertebrae were analysed using a 2D configuration from the left lateral view. The variation along the vertebral series suggests the identification of cervical, abdominal, dorsal, and caudal groups. The first three (cervical) elements and the $10^{\text {th }}$ (supra-dorsal) structure show peculiar morphologies and local adaptations, associated with neck angulation and dorsal fin muscles, respectively. The vertebral size decreases from the anteriormost element backward, with some local variation at the dorsal area. Major changes are related to allometric variation at the neural region. The caudal elements are characterised by a marked size decrease, with consequent allometric shape changes involving the rotation of the posterior vertebral opening. This allometric trajectory leads to a natural ventral bending of the tail, promoting its prehensile function. This morphological survey suggests an interesting structural network between posture, locomotion, and vertebral anatomy, underlying the main functional changes in the Hippocampus biomechanics. Geometric morphometrics is rather suitable to approach metameric studies in terms of serial variation and functional adaptations.

KEY WORDS: Metamery; Serial homology; Shape analysis; Seahorse; Axial skeleton.

\section{INTRODUCTION}

The first Owen's (1843) definition of homology as «... the same organ in different animal species under every variety of form and function», and its immediate extension to metameric elements, still represents a central concept in evolutionary biology. The evolutionary developmental approach to the study of serial homology is supporting new interesting interpretations of the diversity of life and it is the focus-point of a current scientific debate (Staton, 2000; Mindell \& Meyer, 2001; Minelli, 2002). A rebirth in the study of metamery has been followed in the last decades after that the developmental biology has met a molecular approach (e.g., Minelli et al., 2000; Abouheif \& Wray, 2002; Minelli $\&$ Fusco, 2004). Now we are beginning to understand the genetic bases behind specific segmentation patterns in Arthropods and Vertebrates. Hox genes are among those specific developmental genes responsible for the segments differentiation along the longitudinal body axis. They are involved in quantitative and qualitative changes in the appendages of arthropods, or in the development of vertebrae in mammals (Lewis, 1978; Nüsslein-Volhard \& Weischaus, 1980; Galis, 1999; Minelli, 2000; Galis et al., 2001). Within the Syngnathidae, Hippocampus is the more diversified genus, being currently represented by a number of species ranging from 32 (Lourie et al., 1999) to 45 (http:// www.fishbase.org) recognized taxa. Seahorses are found primarily in warm and coastal waters; they are worldwide distributed in tropical and temperate regions, roughly from 50 degrees north to 50 degrees south latitude. Seahorses and few other syngnathids are the only fishes that can bend the tail in a strict spiral used as a prehensile appendage. Considering the 52 genera of syngnathids (Nelson, 1994), the dorso-ventral tail bending ability have been evolved only in Hippocampus and in few other taxa like Acentronura and Amphelikturus (Dawson, 1985). Though Solenostomidae the sister-group of Syngnathidae - share many characters and a common evolutionary history with them, the new movement of seahorse tail can be considered a real apomorphy into this family (Hale, 1993). Seahorses spend

\footnotetext{
* Department of Health Science, University of Rome Foro Italico, Rome, Italy.

** Department of Animal and Human Biology, University of Rome La Sapienza, Rome, Italy.
} 
most of time attached to algae and corals by their prehensile tail, cryptic with the surrounding substratum (Blake, 1980; Lourie et al.). Swimming is highly specialized through rapid oscillations of the dorsal fin (Breder \& Edgerton, 1942; Ashley-Ross, 2002), the caudal fin being absent and the whole caudal region having lost its role in locomotion. Locomotion by fin undulation is widespread among fishes that need of a slow speed and high manoeuvrability within complex, obstacle-strewn environments such as coral reefs (reviewed in Lindsey, 1978). A unique way of swimming called hovering (Videler, 1993) coevolved with the seahorse new anatomy and the camouflage ability. Seahorse tail has also an important function in the social behaviour of these animals: males strongly hang each other with the tail when competing for females and it is softly used by the couple during mating (Vincent, 1994). The new tail bending skills and posture of seahorses have probably opened ecological alternatives that revealed advantageous considering the high number of species into this genus. At least theoretically almost all pipefishes have preserved a lateral movement of the tail and in most cases the tail fin as well. Compared with the general organization of the biomechanical system of other fishes, Hippocampus undergoes substantial modifications in relation to the proportions of the myotome parts (Rauther, 1925; Hale, 1996). Previous experimental approaches have demonstrated a direct involvement of a couple of cordonlike median ventral muscles, and their connection with hemal spines (Hale, 1996). Nevertheless, significant innovations in the axial skeleton of seahorses have not been explored.

In this paper we explore the variation of the vertebral metameric series in Hippocampus hippocampus through geometric morphometrics, thin-plate spline, and bending energy (e.g., Bookstein, 1991; Rohlf \& Marcus, 1993; Adams et al., 2004). Metameric elements represent a specific case of morphological variation, in which the "Operational Taxonomic Units" are not randomly distributed and sampled but ordered following a progressive natural series along the vertebral column. Thus, shape variables can be regressed and compared by virtue of their serial position.

The null hypothesis is that along the vertebral series differences are lacking (e.g., randomly distributed), or they are associated with structural changes related to size-effects. If this hypothesis will be falsified, specific adaptations or neomorphic relationships (thus, derived when compared with a general basic vertebral structure) will be revealed as local shape differences of the vertebral elements.

\section{MATERIAL AND METHOD}

Sample and configurations. Several specimens of $H$. hippocampus were obtained and examined during summer 2002, in front of Gioiosa Jonica (Reggio Calabria, Italy, Ionion Sea, Mediterranean), from accidental capture by fishermen nets. One adult female was selected according to its good preservation status and lack of pathological or subpathological alterations. Only one individual has been used because of the explorative purpose of this study. The fresh specimen has been cleaned by immersion in $2-3 \% \mathrm{KOH}$ solution for few hours. Digestion of skin and soft flesh parts has exposed the skeleton and the characteristic bony plates that cover syngnathids body. The vertebral series include the entire vertebral set from the $1^{\text {st }}$ to the $36^{\text {th }}$ element. Unfortunately, the $34^{\text {th }}$ element was missed during the preparation process.

Pictures in norma lateralis of each vertebra were obtained positioning the element over the vertebral lateral process or the basapophysis where it was present. A scale bar was used as metric reference.

Seven 2D landmarks were sampled on each vertebra (Fig. 1) through tpsDig 1.20 (Rohlf, 1998a): 1) inferior edge of the anterior vertebral body opening; 2) superior edge of the anterior vertebral body opening; 3) first anterior tip of the vertebral neural arch; 4) central tip of the vertebral neural arch; 5) last posterior tip of the vertebral neural arch; 6) superior edge of the posterior vertebral body opening; 7) inferior edge of the posterior vertebral body opening. The three landmarks that define the neural arch (LM3, 4, 5) describe three main tips that characterise the seahorse vertebrae. These tips are present in all the elements of the series, but they assume different forms along the column; they appear as well defined spines in some vertebrae, or just tips and maximum curvature points (sensu Bookstein, 1991) in others. Furthermore, the two vertebrae localised under the dorsal fin have six neural spines each. We chose the fourth spine as the central neural landmark, considering that it originates from the middle of the centrum. Even if the landmarks of the neural arch are not necessarily homologous within the vertebral morphology, they are able to represent the morphological organisation of each vertebra, showing the main neural structures involved in the vertebral biomechanics (e.g., muscles and tendons attachments).

According to this configuration, for practical use each vertebra can be theoretically divided into four quarters, depending upon the position in the antero-posterior (cephalic vs. caudal) and supero-inferior (neural vs. ventral) direction. The caudal group forming the tail was analysed independently, including also the hemal spine tip to the configuration through an additional landmark.

The inter-vertebral inclination of the caudal series was 


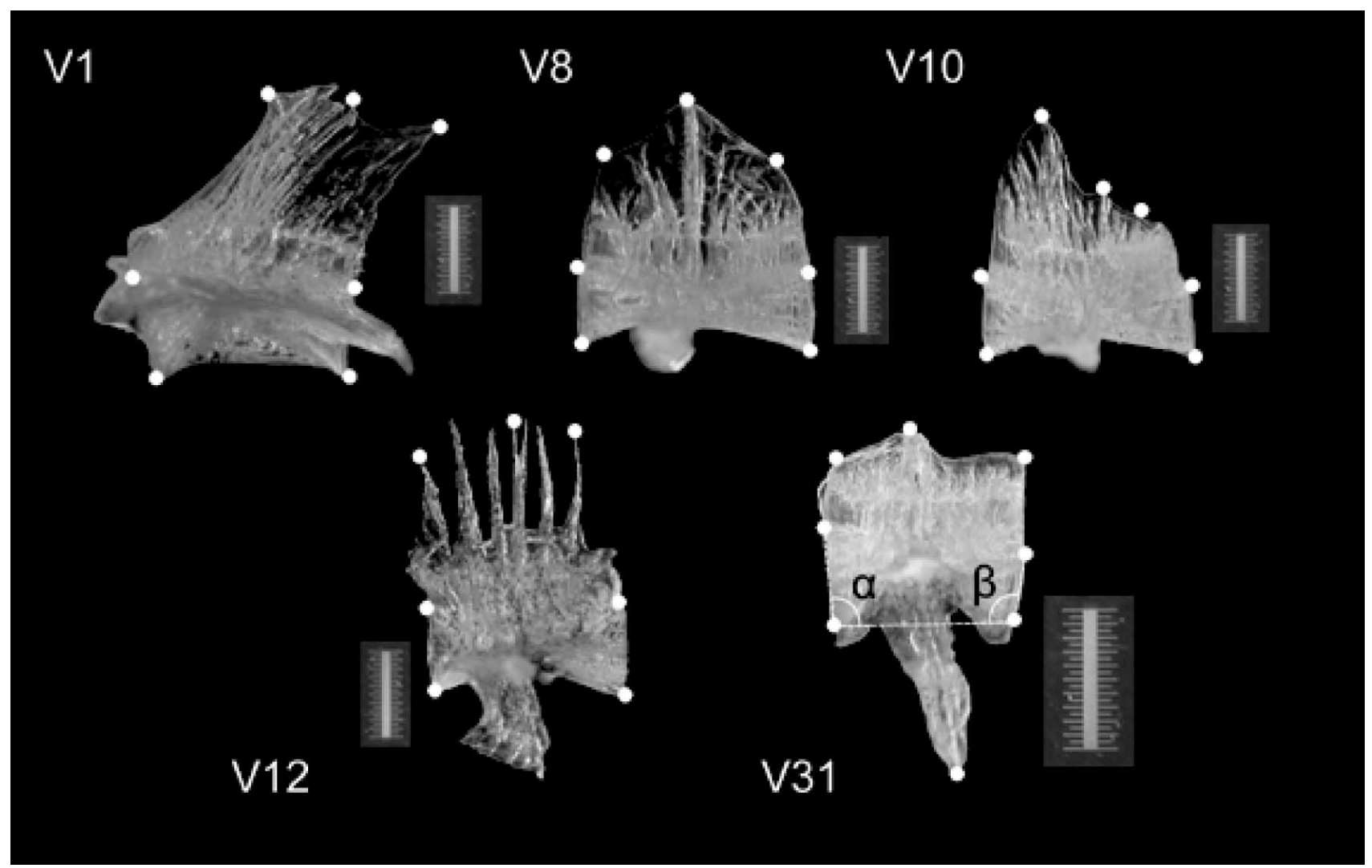

Fig. 1. Landmark configuration, shown for the main vertebral types: cervical (V1), abdominal (V8), supra-dorsal (V10), dorsal (V12) and caudal (V31). In the latter, the anterior and posterior angles are also reported.

considered calculating the angles formed by the vertebral base (a baseline between $1^{\text {st }}$ and $7^{\text {th }}$ landmarks) and the anterior (a) and posterior (b) openings of the vertebral bodies. Angles were calculated using ScionImage (http:// www.scioncorp.com).

Statistics. Centroid size was used as a vertebral size index, calculated as the square root of the sum of squared distances of the set of landmarks from their centroid (Marcus et al., 1996).

Coordinates were superimposed by Generalised Procrustes Analysis, that is by translation to a common centroid at the origin of a reference coordinate system $(0,0)$, scaling each element at unitary centroid size, and finally rotation as to minimise the sum of square distances between correspondent landmarks (Bookstein, 1991). Procrustes distances (defined as the square root of the sum of the squared differences between correspondent landmarks after Procrustes superimposition - see Bookstein, 1996) from the 2D coordinate systems were computed using tpsSmall 1.19 (Rohlf, 1998b) and used to quantify the morphological differences between the vertebrae configurations. Using the Procrustes distance matrix, the single elements were clustered following the unweighted pair-group method through arithmetic averages procedure (UPGMA) to assess the degree of morphological similarity. Phenograms were computed using Syn-Tax 2000 (Podani, 1997; Podani, 2000). This descriptive approach is useful to identify the principal morphological determinants, and to investigate functional separations within the vertebral continuum. Differences between elements and along multivariate axes were visualised through the thin-plate spline interpolation function, that enables to show the minimum deformation of a square grid from a reference to a target configuration, according to the vector displacement between correspondent landmarks (Bookstein, 1991). Procrustes superimposition, pairwise comparisons, and thin-plate spline were performed using Morpheus et al. (Slice, 2000). Bending energy was calculated using tpsSpline 1.15 (Rohlf, 1997). In geometric morphometrics bending energy refers to a variable quantifying the minimum energy required to warp a conventional surface from a reference to a target coordinate system (Bookstein, 1991; Rohlf, 1993). This function was derived from the studies on the mechanics of thin metal plates, and associated with the results obtained through thinplate spline interpolation function (see also Bookstein, 2000). It is not influenced by affine/uniform shape variation (that 
is, by those differences induced by linear stretching or shearing of the whole structure), but by non-affine (i.e., localised onto specific areas) changes, depending upon large vs. small-scale differences. In this sense, it is not a common measure of dissimilarities. It quantifies the magnitude of variation but not its direction. Considering the serial distribution of the vertebral structures, it may provide useful information on the morphological changes along the vertebral spine, identifying trends or rupture of continuities. Principal Component Analysis (called Relative Warp Analysis in geometric morphometrics) was performed and visualised by tpsRelw 1.18 (Rohlf, 1998c). Correlation between shape and size changes was tested using tpsRegr 1.20 (Rohlf, 1998a) and tpsPLS 1.12 (Rohlf, 2002). The first program performs a multivariate regression of each shape variable onto centroid size, the second computes a symmetric regression between centroid size and a linear combination of all the shape variables (see Corti \& Rohlf, 2000). A preliminary intra-observer error analysis performed through repeated samples considering Procrustes distances and Principal Component Analysis showed only minor variations within the resulting morphospace.

\section{RESULTS}

Cluster analysis and vertebral shape and size. Clustering the vertebral configurations according to the Procrustes distances, the elements are separated into phenetic groups that allow the recognition of major morphological classes (Fig. 2). The first and second vertebrae are the most outstanding in terms of shape, as well as the $10^{\text {th }}$ segment. The morphology of the third vertebra is more comparable with the rest of the series, even if grouped with the caudal ones. Two major clusters can be recognised within the remaining variation. The first one includes the vertebrae underlying the dorsal fin (V11 and V12), and those of the body with the exclusion of the tail. We call the first two dorsal vertebrae, and the others abdominal vertebrae. There is a good partition between the vertebrae preceding and succeeding the dorsal one (with the exception of V9), and it is therefore possible to divide into pre-dorsal (V4 to V9) and post-dorsal (V13 to V19) abdominal series. According to the proximity with the dorsal fin and the particular shape, V10 can be labelled as supra-dorsal vertebra, to stress its peculiar identity. The second major cluster includes all the "caudal vertebrae" (V20 to V36), further divided into three groups according to the proximal, intermediate, or distal position (with the exception of V27). Even considering their heterogeneous shape, the three cephalic elements can be presently called cervical vertebrae, mostly with the aim to separate them from the other structures. The cophenetic correlation coefficient between Procrustes distances and phenetic clustering (that is, the correlation between the actual shape distances and the phenogram distances) is 0.80 , suggesting a good resolution of the similarities. This morphological classification will be useful for the following description and analyses.

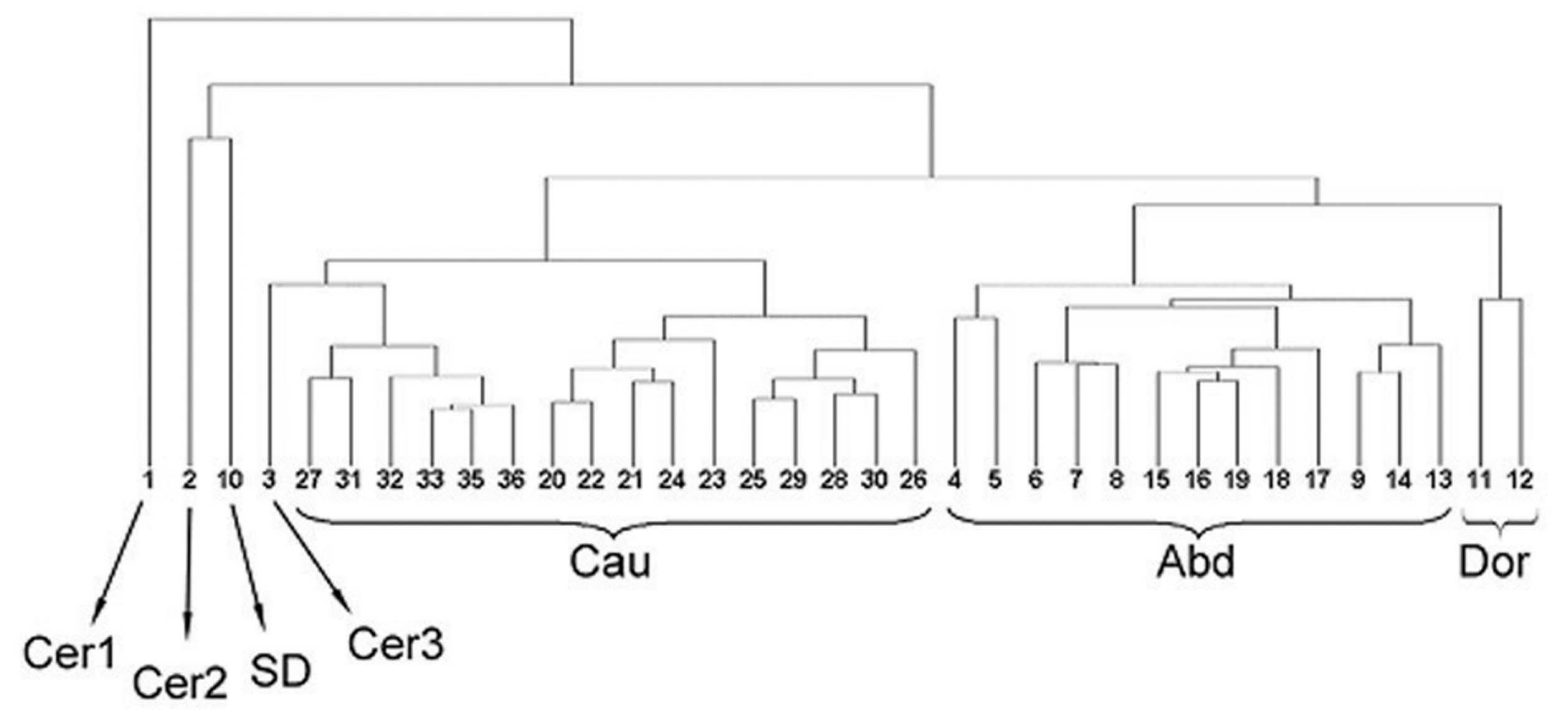

Fig. 2. Clusters (UPGMA) based onto the Procrustes distances; abd: abdominals; cau: caudals; cer: cervicals; dor: dorsals; SD: supradorsal. Numbers refer to the vertebral position. 
Fig. 3 shows the thin-plate spline distortion grids after Procrustes superimposition from the consensus shape (overall average configuration) to each group-specific mean shape according to the clusters suggested on the basis of the phenogram (or versus specific vertebral shapes if no grouping is recommendable). These groups can be shortly described as follow:

Cervical vertebrae: This group is heterogeneous, with the three elements showing different shapes. The first is mainly characterised by a compression of the posterior area, backward bending of the entire structure and protruding of the neuro-caudal edge. The second vertebra shows the enlargement of the neuro-cephalic quarter, and reduction of the neuro-caudal one. The third cervical vertebra is the less diversified, showing just a minor anterior enlargement of the upper neural edge.

Abdominal vertebrae. Compared to the consensus average shapes, the abdominal structures are characterised by a slightly shorter and higher neural area (that is, a vertical stretching of the upper part). This pattern is more evidenced in the pre-dorsal segments than in the post-dorsal ones.

Dorsal vertebrae: The two dorsal elements show the vertical stretching of the posterior body, with consequent bending of the whole structure becoming relatively shorter. The supradorsal vertebra is conversely characterised by a marked development of the neuro-cephalic quarter, and reduction of the neuro-caudal area. The pattern is similar to that expressed in the $3^{\text {rd }}$ vertebra, just more stressed and exaggerated. Furthermore, in the $10^{\text {th }}$ element the enlargement of the neuro-cephalic area is more vertically directed.

Caudal vertebrae: These structures are extremely close to the consensus shape because of their large number within the sample size, just a bit more flattened and anteroposteriorly elongated.

The variation of the centroid size along the vertebral series shows a size decrease from the first to the last structures (Fig. 3). The cervical elements are the largest, decreasing from the first to the third. The pre-dorsal vertebrae are bigger than the post-dorsal ones, and a certain size decrease can be recognised along the latter series. The dorsal elements become bigger from the $10^{\text {th }}$ (supra-dorsal) to the $12^{\text {th }}$. The caudal structures become gradually smaller approaching the distal end of the tail.

Bending energy variation. If we plot the bending energy value onto the position of each vertebra (serial sequence) we can figure and quantify the morphological changes along

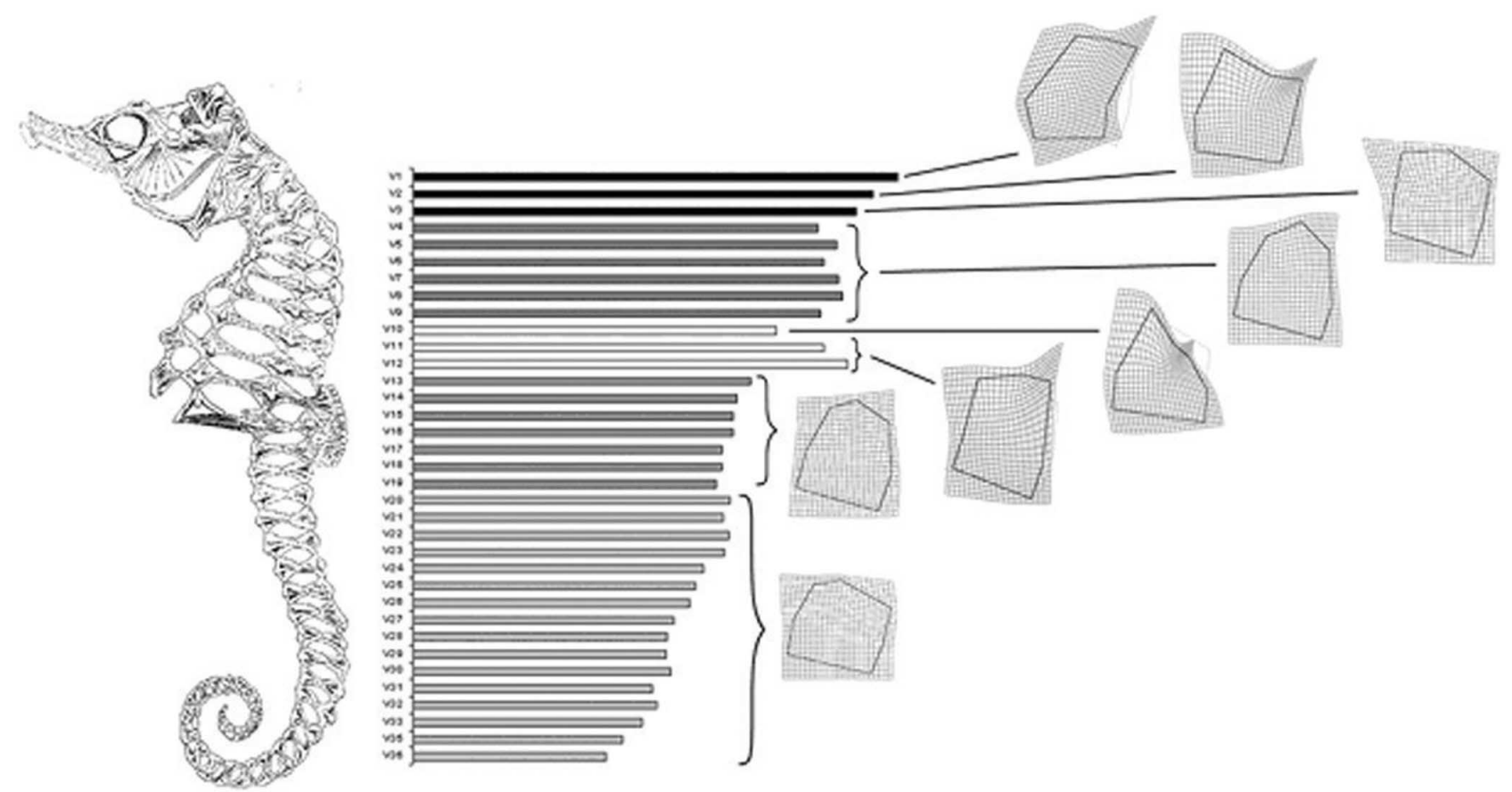

Fig. 3. Vertebral variation in Hippocampus hippocampus. Numbers refer to the vertebral position, associated with centroid size (bars). The deformation grids show the differences between the consensus average shape and the mean shape for each vertebral group (see Fig. 2; pre- and post-dorsal abdominals are split). 
the spinal structure in terms of shape distortion of its elements (Fig. 4). Bending energy can be reported comparing each element with the consensus average shape, or conversely reporting the energy difference between two adjacent vertebrae. In the first case we can consider the overall magnitude of morphological variation according to the sample mean, in the second it is possible to synthesise local morphological discontinuities along the spine. These two approaches are partially redundant, but may also provide some complementary information.

Considering the average bending energy, a large bending stress is localised at the first two cervical elements (mostly at the second vertebra). It is worth noting that the third structure shows a value comparable with the pre-dorsal elements. Furthermore, there is a large amount of changes passing from the $2^{\text {nd }}$ to the $3^{\text {rd }}$ vertebra, which is twice the value reported from the $3^{\text {rd }}$ (last cervical) to the $4^{\text {th }}$ (first abdominal).

The largest amount of variation is displayed at the supra-dorsal element (with high values also for the following two dorsal ones). Along the serial sequence, a marked structural change is reported from the $9^{\text {th }}$ to the $10^{\text {th }}$ (supradorsal) vertebra, but mostly from this element to the following. In contrast, only minor changes are displayed between the two dorsal structures. A low bending peak is localised from the $30^{\text {th }}$ to the $31^{\text {st }}$ vertebrae.

Vertebral shape variation. A Principal Component Analysis was computed onto the less diversified vertebral groups (namely the abdominal and caudal series), to assess the major structural patterns within these supposed non-specialised (or less-specialised) elements.

Fig. 5 plots the vertebral configurations onto the shape space of the first two principal components of variation, explaining together $85.7 \%$ of the variance. The first component $(74.4 \%)$ separates the abdominal from the caudal structures. The distance of the caudal elements from the abdominal ones is proportional to the position along the vertebral sequence, according to the phenogram partition. The abdominal group is characterised by vertical stretching, while the caudal elements show a progressive antero-posterior enlargement and vertical flattening. The pattern is particularly evidenced at the neuro-caudal area of the vertebrae.

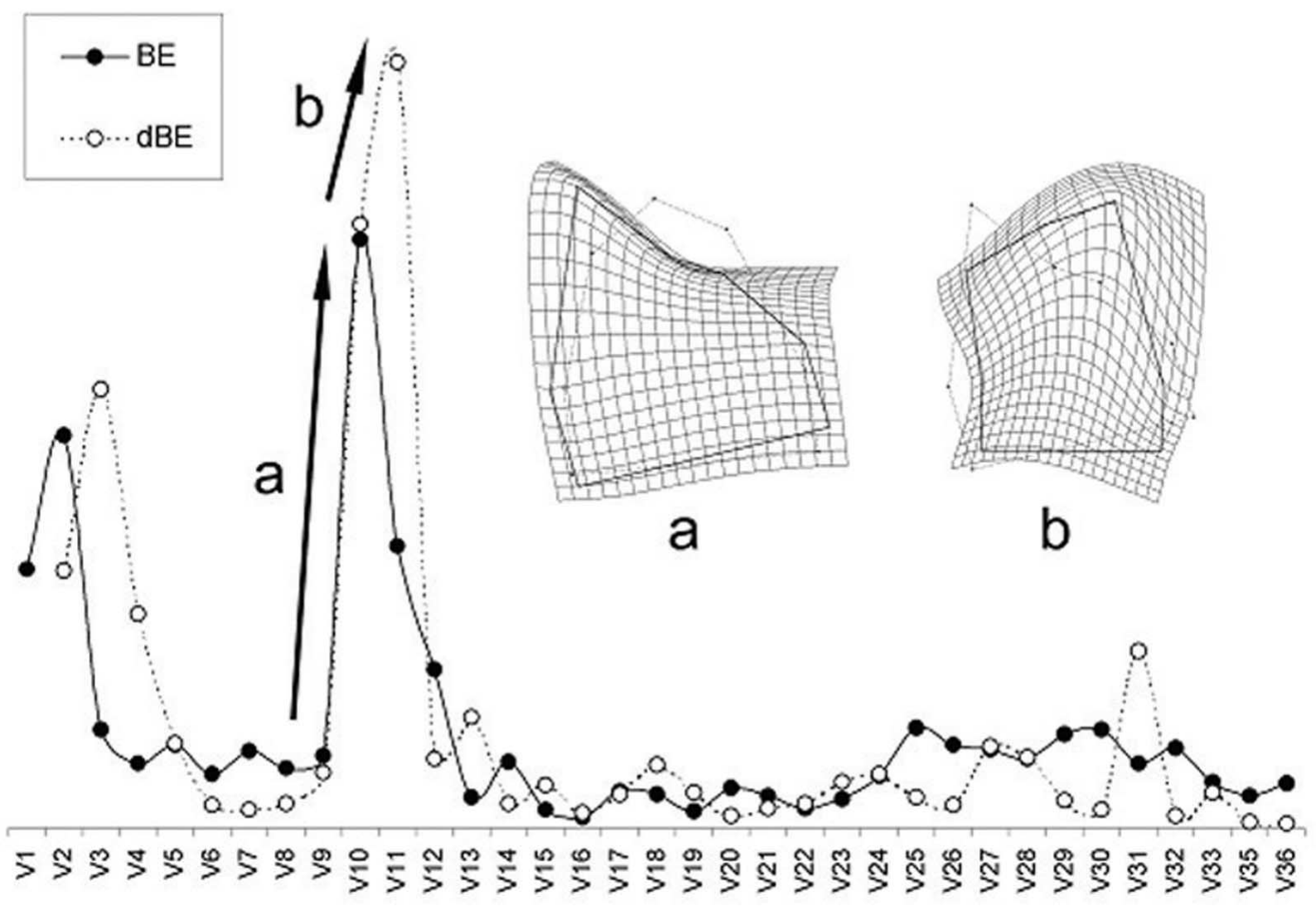

Fig. 4. Bending energy serial profile. The bending energy value is plotted onto the vertebral sequence, both computed from the consensus to each element (BE: solid line) and between contiguous elements (that is, from the previous to the following; dBE: dashed line). The deformation grids show the differences between $9^{\text {th }}$ and $10^{\text {th }}$ (a) and between $10^{\text {th }}$ and $11^{\text {th }}(\mathrm{b})$ elements, respectively. 


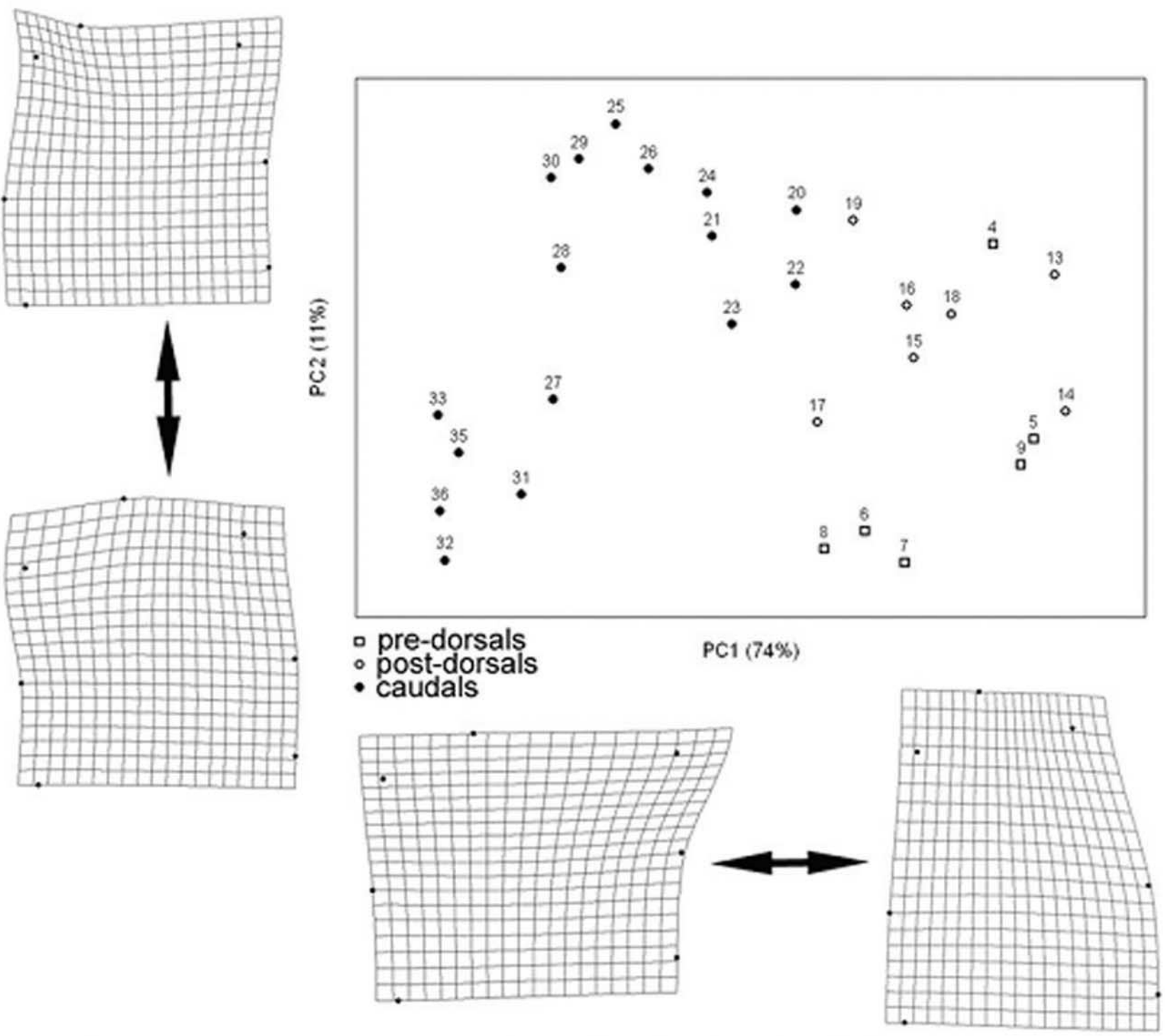

Fig. 5. First and second Principal Components Analysis of the abdominal and caudal elements. Thin-plate spline deformation grids show the shape changes along these two vectors at the extremes of the respective distributions.

The second component (11.3\%) separates the pre and post dorsal abdominal vertebrae (with the exception of V4), and the most terminal caudal structures from the rest of the tail. This vector is associated with enlargement (in the predorsal abdominal and in the terminal caudal group) or conversely reduction (in the post-dorsal abdominal group and in the anteriormost caudal vertebrae) of the neurocephalic vertebral surface.

Shape changes are statistically size-related (Generalised Goodall F-test: $\mathrm{F}=28.5$, df $=10.27, \mathrm{P}<$ 0.00001 ), with a marked correlation coefficient (partial least square regression, $\mathrm{R}=0.84$ ). Nevertheless, this allometric component is entirely represented by the only $\mathrm{PC} 1(\mathrm{R}=0.82)$, and the vectorial displacement along the allometric trajectory is the same expressed along the first axis of variation (Fig. 6). The pre-dorsal abdominal vertebrae do not show a clear allometric component, while the post-dorsal and caudal series possibly suggest two different allometric patterns. Considering the sample size of the caudal structures and the functional importance in Hippocampus, the caudal sub-sample will be analysed independently in the following section.

Variation in the caudal vertebrae. A Principal Component Analysis was performed onto the caudal series (from the $20^{\text {th }}$ element backward), using the configuration including the hemal spine. The first two components account for the $84.5 \%$ of the total variance (Fig. 7). PC1 (72.7\%) sorts the 


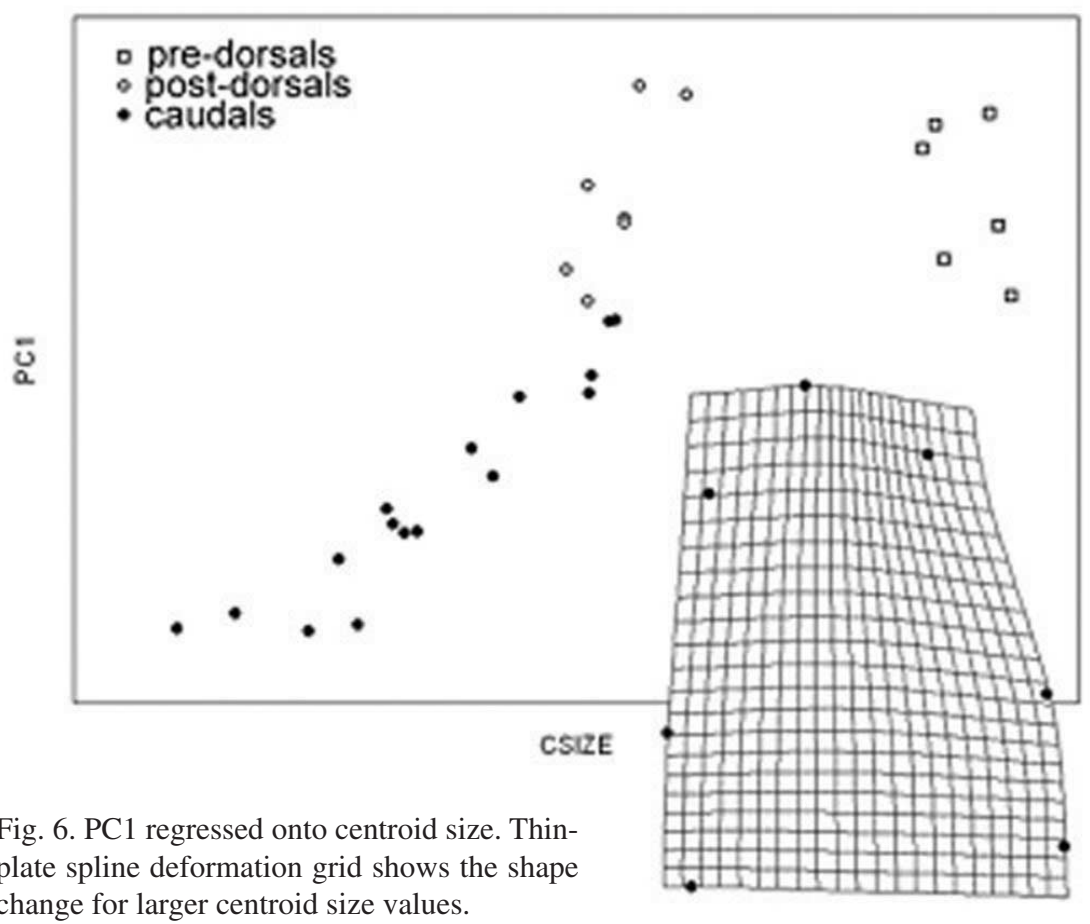

vertebrae from the most cephalic to the most caudal groups. This component involves (from the anterior towards the posterior positions) the antero-posterior enlargement of the neural area, mostly considering its anterior quarter. PC2 (11.8\%) separates four elements positioned at the centre of the caudal series (V25, $\mathrm{V} 28, \mathrm{~V} 29, \mathrm{~V} 30$ ), because of the relative development of the neuro-caudal quarter and reduction of the neuro-cephalic one.

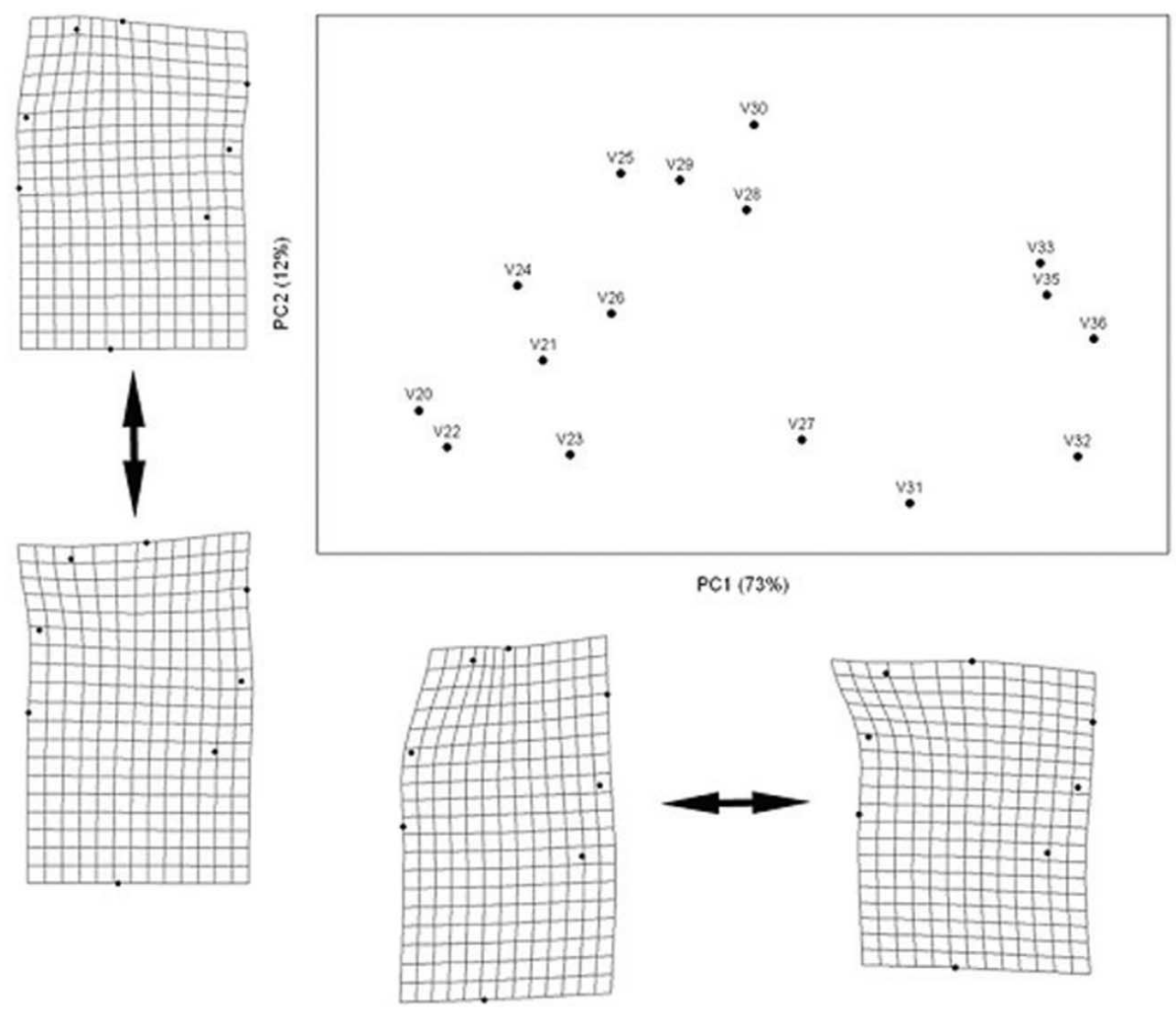

Fig. 7. First and second Principal Components Analysis of the caudal elements. Thinplate spline deformation grids show the shape changes along these two vectors at the extremes of the respective distributions. 
This first principal component is highly correlated to both centroid size $(\mathrm{R}=-0.94 ; \mathrm{p}<0.001)$, and vertebral serial sequence $(\mathrm{R}=0.95 ; \mathrm{p}<0.001)$. The correlation between centroid size and vertebral sequence in this caudal subset is extremely large $(\mathrm{R}=-0.99 ; \mathrm{p}<0.001)$. The anterior and posterior angles of the vertebral body (see Fig. 1) were measured from the 2D coordinate systems, and regressed onto centroid size, shape vector, and vertebral position. The anterior angle does not show any significant correlation, while the posterior one is correlated with $\mathrm{PC} 1(\mathrm{R}=0.79)$, centroid size $(R=-0.76)$, and vertebral sequence $(R=0.75$; $\mathrm{p}<0.001)$. The sum of the angular deformations of the centra represents a measure of the actual curvature of the tail, covering 180 degrees after 15 vertebral elements.

The correlation with size, sequence, and angles is limited to the PC1, with only a minor increment of the correlation coefficients including the following shape components through multiple regression and partial least square analysis. The allometric component through the entire shape space $(F=26.5, d f=12.17, p<0.00001 ; R=0.95)$ shows the same warp described for the first principal component.

\section{DISCUSSION}

Morphological variation in the seahorse vertebral system. Teleostean anatomy mainly distinguishes abdominal and caudal vertebrae on the presence of a couple of ventro-lateral basapophyses for the attachment of ribs in the first group and a closed hemal arch in the second. Hippocampus, displays a unique structural arrangement of the axial skeleton compared to the basic organization of teleosts, with changes in the relationships of the metameric elements (Rauther; Hale, 1996). Such outstanding position of the seahorses within the framework of the teleostean variability provides a very good opportunity to analyse a discrete and well delineated evolutionary case-study. The structural configuration of the vertebral series accounts for the vertical locomotion and posture, while the caudal morphology supports the prehensile properties of the tail. This study is aimed at characterising the vertebral series in H. hippocampus, testing the pattern of shape variation through a geometric approach. Using geometric morphometrics is possible to recognise in this taxon different morpho-functional groups of vertebrae, according to their shape in lateral view. These groups can be conventionally defined according to their position and role along the vertebral sequence.

The vertebral series in Hippocampus shows variations both in size and shape. Concerning size, there is a general decrease from the cephalic to the caudal extremes. Nevertheless, changes are not always gradual. A reduction is evident mostly after the dorsal elements, and a homogeneous decrease in size is only displayed in the caudal set. The three cervical vertebrae are larger anteriorward as well. The supra-dorsal vertebra is smaller than the surrounding vertebral structures. The large size of the two following dorsals represents a discontinuity with the smaller tenth vertebra, even more evident when compared with the subsequent vertebral groups. Excluding the caudal series, changes in shape do not follow a shared and sequential structural trajectory. That is, non-caudal vertebrae do not show a gradual morphological variation associated to size or position along the spine. Rather, there are local differences in specific and specialised elements, such as those associated with the neck angulation and dorsal fin biomechanics. Variations are localised mostly at the neural districts, with scarce or no differences in the basal structures. Therefore, changes are related to enlargement/reduction and consequent deformation of the neural arch and spine, without marked changes at the vertebral bodies. In agreement with the size decrease described previously, an allometric variation can be reported after the dorsal elements, mostly considering the caudal set discussed subsequently.

Although in tight proximity, atlas, epistropheus and the third vertebra do not display a shared morphology, neither do resemble other vertebral cluster. Hence, a first cervical complex represents a diversified group including the first three, atypical, and specialised vertebrae. Actually, although the third element is more similar to the caudal series, both its size and shape (according to the bending energy in terms of morphological diversity) are intermediate between the large two anterior cervical elements and the following abdominal vertebrae, acting as a structural "bridge" between two different phenotypes. The vertical posture of seahorse requires a re-orientation of the head that, to preserve the normal anteriorward view ability, should be no more in line with the longitudinal body axis. This arrangement deeply affects the antero-posterior symmetry of the cervical vertebrae, producing a deformation in their vertebral bodies. The two openings of centra are no more parallel and these first vertebrae display a natural curve in the cervical region. Atlas, epistropheus and the third vertebra are strongly connected each other through neural anterior zygapophyses, constraining the articulation of this complex. Actually, in $H$. hippocampus the zygapophyses are maintained only in the cervical structures and completely absent in the following vertebrae, and these differences can be possibly related to the vertical posture of the seahorse.

A group of vertebrae before (from V4 to V9) and after (from V13 to V19) the dorsal fin shares a common lateral shape. Considering their reduced specialisation and limited size variation (mostly taking into account the size stability 
within the former cluster), we may assume these structures as the less derived along the whole spinal series. They have been named pre-dorsal and post-dorsal abdominal vertebrae, respectively.

Two elements (V11 and V12) that fully lie under the dorsal fin, and that tighten anatomical and functional relations with this structure, group together and are referred to as dorsal vertebrae. The vertical posture of seahorse and its main way of locomotion through rapid dorsal fin movements (Consi et al., 2001; Ashley-Ross) have deeply affected the neural areas of these vertebrae. The proximal radials are interdigitated with the neural spines (Consi et al.) that are strongly developed as long and robust spines. Through a rigid connection with the underling dorsal vertebrae the proximal radials of the seahorse offer a solid structure for the fin movement. Although also the pectoral fins are important for the seahorse locomotion (Blake, 1976), their related muscles are more associated with the pectoral girdle than with the vertebral column.

The $10^{\text {th }}$ (supra-dorsal) vertebra displays an outstanding position in the shape space, suggesting an extremely specialised role within the spine biomechanics. Its shape divergence is mainly consequence of a marked antero-posterior asymmetric deformation of the dorsal region, with strong reduction of the posterior half. Although its limited size, the morphological differences between this element and the previous one are extremely marked, without structural transitions accounting for such phenotypic divergence. In contrast, the two dorsal vertebrae display a specific enlargement opposite to the generalised cephalocaudal reduction, but in terms of quantitative variation (i.e., bending energy) they provide a morphological transition towards the following structures. The supra-dorsal vertebra has no direct bony connection with the above fin, while the following dorsal ones are directly joined to its pterigiophores. Actually, the dorsal elements are involved in the dorsal fin oscillations through the connection of inclinator and depressor muscles between fin rays and their dorsal region. Nevertheless, these muscles reach the caudal areas of the supra-dorsal element too, inducing its asymmetric upper development through a dynamic tension. The peculiar shape of this structure is associated with a neuro-caudal reduction more than with a neuro-cephalic development, as suggested by the small centroid size. Figure 8a shows the supra-dorsal configuration compared with a pre-dorsal abdominal one (V6) with same ventral length visualised onto the respective anatomical dissection. The two shapes were superimposed using the ventral landmarks 1 and 7 as baseline. This comparison can be useful considering that these two elements have the same actual antero-posterior length, and the following superimposition allows to compare both size and shape variation together. As supposed on the basis of the size and shape information independently, the supra-dorsal vertebra is characterised by a marked reduction of the neurocaudal quarter. The neuro-cephalic area is more developed and rather tilted backward, as to account for the posterior compression. It may be then inferred that the surrounding anatomical environment (tendons, muscles and epigenetic factors) that deeply affects the dorsal vertebrae V11 and V12, produces an antero-posterior asymmetry only in the supradorsal element V10. The involvement of half element is in agreement with the development of the embryonic myotomes, originating each vertebral element by the fusion of the posterior and anterior halves of the anterior and posterior metamers, respectively (Grassé, 1958). The anteriormost fin ray is actuated by the elevators muscles, a supplementary pair of bilaterally arranged structures. This single couple of muscles accomplished for the elevation of the entire fin (Consi et al.). The elevator muscles, acting together, can raise the anteriormost fin ray and consequently the entire fin because all of the fin rays are mechanically coupled (Consi et al.). Hence, considering the vertical posture of seahorse the supradorsal vertebra has the additional function of "anchoring" the fin, supporting the elevator muscle tension like a "nail" fastening a picture. This information should be considered carefully when analysing the biomechanics of movement in seahorses, in terms of tension and posture (Fig. 8b). Assuming $t$ as the tension vector originating from the interaction between vertebrae and dorsal fin, its projection along the gravitational axis ( $\mathrm{y}$ ) must be equal and opposite to the gravitation force $(\mathrm{mg})$. $\tau \mathrm{y}$ can be calculated as the product of $t$ and the sinus of the angle $(\alpha)$ between the plane orthogonal to the gravitational axis and the vector of the tension. Thus, $t$ can be calculated as the ratio between $\mathrm{mg}$ and sen. Accordingly, the tension decrease as the angle of insertion between the dorsal fin and the vertebral axis increases. So, the peculiar morphology of the supradorsal vertebra must be interpreted in terms of genetic/physiological adaptation to the biomechanical environment associated with the following dorsal fin and vertical posture, related to a biomechanical decrease of the tension exerted along the fin/vertebrae interaction.

The pipefish Syngnathus abaster is likely to represent the original structure and locomotion preceding the specialisation of $H$. hippocampus. In $S$. abaster the posture is horizontal, and the dorsal fin is mainly attached to the $16^{\text {th }}$ vertebra. It is worth noting that in this taxon the 14th element is structurally analogous to the H. hippocampus pre-dorsal abdominals, the $16^{\text {th }}$ element shows the attachments for the pterigiophores, but the $15^{\text {th }}$ element does not show a morphology similar to the $H$. hippocampus supradorsal vertebra (Fig. 9). Therefore, while in $H$. hippocampus the variation between the pre-dorsal and the dorsal elements is morphologically discrete, in S. abaster this structural passage 

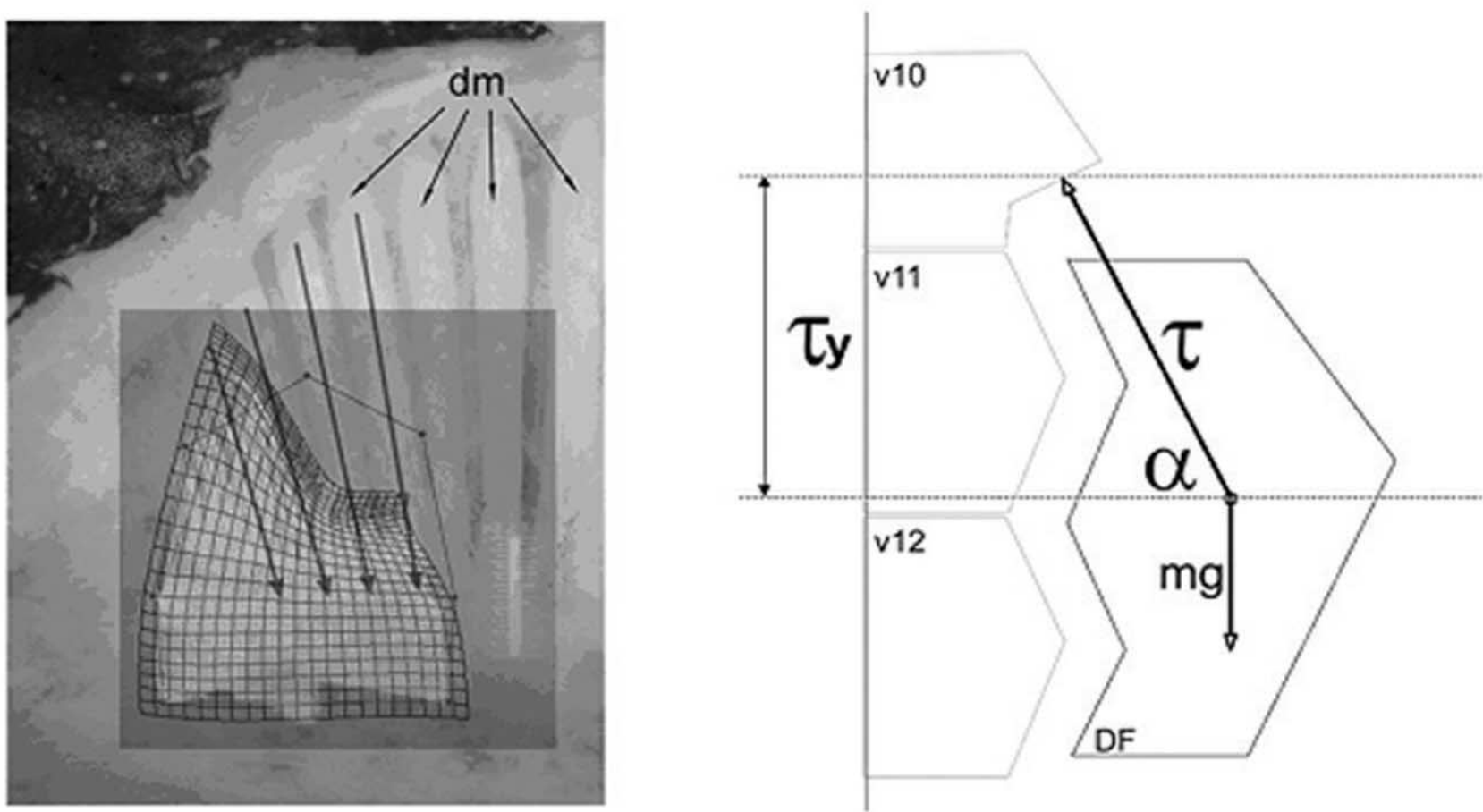

Fig. 8. a) The supra-abdominal element is visualised onto a lateral dissection showing the muscular system of the dorsal fin (dm: dorsal muscles). The distortion grid shows the difference between the supra-dorsal vertebra and an abdominal one (V6) with the same body length, after baseline superimposition on this diameter. b) Schematic diagram of the forces involved in the relationship between vertebrae 10-12 (V10-V12) and dorsal fin (DF) - see text for discussion.

is more gradual. From the horizontal locomotion of Syngnathus to the vertical posture of Hippocampus, the vertebra anterior to the dorsal fin changes from a more simple transitional element into the highly specialised supradorsal structure of the seahorse, that shows development of the anterior neural areas and compression of the posterior neural ones. Of course, this hypothesis does not involve necessarily considerations on homology between the elements considered, and it must be intended just in terms of structural analogy.
Allometry and functional adaptations of the caudal vertebrae. The main modifications for the tail bending ability refer to muscles, axial skeleton and tendons, that in other fishes allow lateral undulations of the tail. Solenostomidae, considered the sister-group of Syngnathidae, share many characters with them as a consequence of their common evolutionary history but they lack of the ventral tail bending skill. Therefore, we can assume that this character is derived into Syngnathids (Hale, 1996).

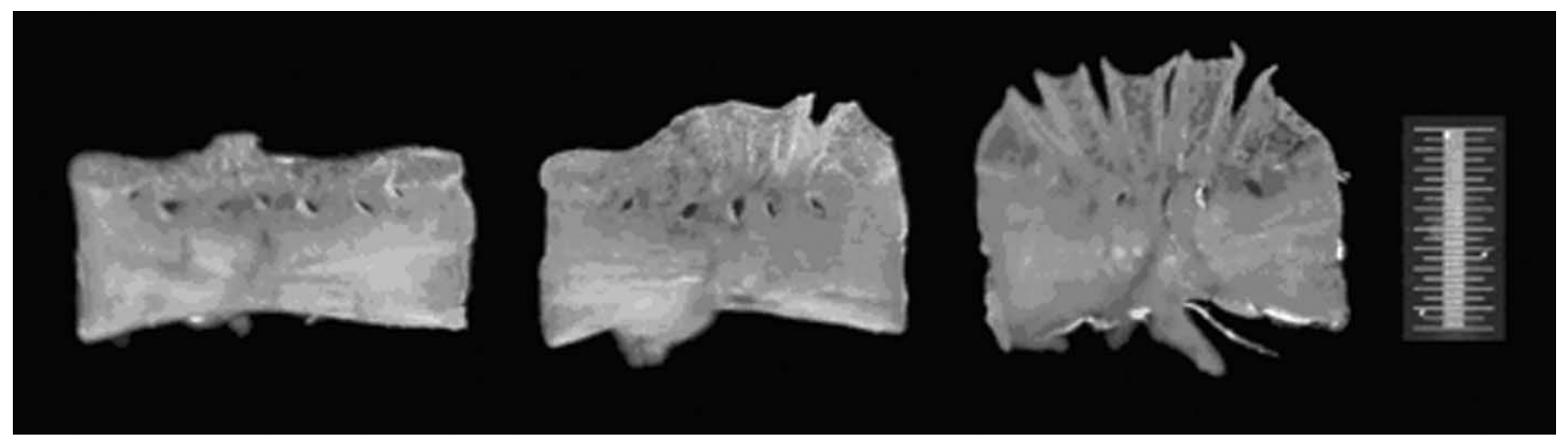

Fig. 9. Vertebrae 14 (abdominal), 15 (pre-dorsal), and 16 (first dorsal) in Syngnathus abaster (left side). 
Vertebrae directly involved in the tail prehensile movement (caudal elements) show a specialised metameric sequential variation, largely based onto allometric changes. Vertebrae become smaller from more anterior to more posterior positions. As size decreases, the neural areas become relatively larger. Anteriorly, the vertebral opening does not change its relative orientation, and the neural enlargement involves a deformation of the upper parts onto the vertebral body. In contrast, while the neuro-caudal quarter becomes relatively larger, the posterior vertebral opening rotates accordingly, increasing the angle between the anterior and posterior surfaces. Actually, these kyphotic vertebrae show a trapezoidal shape in the sagittal plane, rather than a rectangular shape (as in normal centra). These allometric changes account for the main morphological variation along the caudal series, and the correlation between size, shape, posterior angle, and serial position, are very high. That is, a natural curvature of the tail is the structural result of a reduction in the vertebral size, making the tail a spiral that becomes more tightened toward the end.

Therefore, seahorse ventral tail bending is not only associated with muscle activity, but also to the skeletal structure itself. Because of such morphology, seahorse tail can bind to complex substrates maintaining a vertical posture of the rest of the body thanks to the evolution of a structurally bended tail that minimizes muscles strength, with an increased energetic efficiency.

A further note should be provided concerning the relationship between muscles and vertebrae. Main deformations of vertebrae and fins have been documented in a vast literature about morpho-anatomical abnormalities that occur in reared fish populations (reviewed by Divanach et al., 1996). Three basic types of deformities exist, assorted by the direction of their curvature. Kyphosis is an abnormal dorsal curvature (Koumoundouros et al., 2002; Sfakianakis et al., 2003), lordosis a ventral bending (Chatain, 1994; Divanach $e t$ al., 1997) and scoliosis an abnormal lateral curvature of the vertebral column (Lim \& Lovell, 1978). A clear biomechanical association between muscle activity and the abnormal vertebral curvature is largely lacking (Divanach et al., 1997), but lordosis and kyphosis induction has been attributed to increased muscle activity (Chatain; Kihara et al., 2002; Kranenbarg et al., 2005). Nevertheless, in Hippocampus new organisation and proportions of the myotome muscles (Hale, 1996) could play an important mechanical role in the described deformation of centra.

Evolutionary perspectives on the seahorse vertebral system. Seahorse body posture and dorso-ventral tail bending ability probably opened to a series of new ecological opportunities that have been revealed successful and possibly involved in the high speciation rate of the genus. The variation of the bending energy is an interesting tool to investigate shape changes along metameric series, which are composed by natural ordered elements. The seahorse vertebral system is markedly characterised by local adaptations of single elements, mostly related to neck angulation and to the biomechanics of the dorsal fin. Interestingly, this latter structure influences not only as expected the morphology of the underneath dorsal vertebrae, but also the supra-dorsal element, inducing its strong antero-posterior asymmetry. Nevertheless, the remaining less-specialised elements can be grouped into different functional units, according to their role and position along the spine. The tail natural bending is the result of an allometric structural pattern, possibly explained with a different regulation of a common pattern of growth and development, i.e. as the heterochronic result of evolutionary shift in the rate of the same ontogenetic "program". It is well known that allometry and heterochrony may account for large evolutionary changes and patterns (e.g., Gould, 1966; Shea, 1992; Klingenberg, 1998). These processes allow the exploration of morphological/ecological possibilities using the structural plasticity already available within the biological networks, without requiring new arrangements of the biological model. Considering the marked allometric pattern along the caudal vertebrae in $H$. hippocampus, it is possible to hypothesise that such biomechanical and locomotory specialisation may have been evolved using size variations of an existing structural pattern. This assumption can be verified/falsified through the analysis of the ontogenetic development of the seahorse vertebrae, which should provide or discard the evidence of heterochronic variations along the caudal series.

Of course, this process may have had a key-role in the evolution of seahorses, but it does not necessarily represent a common scenario for adaptations to tail prehensility. With exception of the cervical elements, all seahorse vertebrae lack of articular processes like zygapophyses. In contrast, the vertebral column of Chamaeleo (Vertebrata, Reptilia) evolved an analogous dorso-ventral tail bending ability with a prehensile function, but through a direct implication of zygapophyses. These processes are disposed on a vertical plane rather than a horizontal one, allowing a wide dorso-ventral bending and preventing lateral movements (Parker \& Bellairs, 1973).

Considering these results, the metameric vertebral sequence in H. hippocampus offers an interesting evolutionary case-study, taking into account the coexistence of neomorphic traits and allometric structural variants within the same biomechanical system. Both kind of adaptations are derived, but through very different processes. Neomorphies represent reorganizations of the morphogenetic program, involving new relationships between tissues and growth fields. The cervi- 
cal, the dorsal, and supra-dorsal vertebrae shows a distinct morphology compared with the generalised vertebral structure, as result of localised specialisation to neck curvature, fin biomechanics and vertical posture respectively. Interestingly, the passage from more to less specialised elements occurs sometimes more gradually (like considering the possible role of the $3^{\text {rd }}$ cervical element) and sometimes more abruptly (as described by the morphology of the supra-dorsal vertebra). Structural variants, in contrast, represent the expression at different sizes of the same morphogenetic program. The sizerelated shape variations along the caudal series represents such situation. Heterochrony is the best known mechanism to interpret these variations, and considering the differential effect that these processes can exert onto tissues and organs (see Mitteroecker et al., 2005), it is worth noting that the present study suggests even heterochronic gradients along metameric sequences as an actual evolutionary possibility. The admixture of localised rearrangements and heterochronic gradients along a system composed by repeated structures make the seahorses and interesting natural experiments on the concept of "modularity" (e.g., Schlosser, 2002; Pepper, 2003). Modularity refers to the relationship between gene regulatory networks and structural/functional subunits within organisms, and represents a very interesting concept for the present evodevo approaches. Limiting the definition to the anatomical counterpart, it deals with the concept of morphological integration (Klingenberg, 2002). In this sense, the vertebral system of the seahorse shows both the presence of independent elementary structural units (the vertebrae) and the presence of a shared structural environment that organise those units in functional blocks. This is particularly interesting, considering the discrete differences between the genus Hippocampus and its phylogenetically related taxa, without intermediate morphotypes. Of course, considering evolutionary concepts like heterochrony and modularity, it must be kept in mind that the observed phenotype is the result of both genetic (e.g., growth fields) and morpho-physiological (e.g. muscular loadings and tissutal induction) responses, and few can be done without a certain knowledge of these relationships.

\section{ACKNOWLEDGEMENTS}

We are grateful to Roberto Argano for his advices and supervision. The suggestions of Alessandro Campanaro, David Costantini and Patrizia Gallo have been of great help in the drawing up of the manuscript. Federico Falcini kindly contributed to the description of the biomechanical model. Special thanks to Alessandro Minelli and Giuseppe Fusco for their precious comments and authoritative opinions. This paper is funded by the Laboratory of Human Anatomy, Department of Health Science, University of Rome Foro Italico.

BRUNER, E. \& BARTOLINO, V. Variaciones morfológicas en el sistema vertebral del caballo de mar. Int. J. Morphol., 26(2):247$262,2008$.

RESUMEN: El sistema vertebral en Hippocampus hippocampus es altamente especializado, debido a la locomoción vertical y la cola prehensible. Los elementos vertebrales representan un caso especial de cambios morfológicos, siendo estructuras metaméricas organizadas a lo largo de una serie funcional natural. Se investigaron los cambios en la forma, a lo largo de la columna vertebral en $H$. hippocampus a través de morfometría geométrica, con el fin de describir sus patrones funcionales y estructurales. Actualmente, la capacidad de flexión dorso-ventral de la cola en el género Hippocampus es una de las más impresionantes modificaciones morfológicas en la historia evolutiva de los peces. Las vértebras se analizaron mediante una configuración 2D de la vista lateral izquierda. La variación a lo largo de la serie vertebral sugiere la identificación de grupos cervicales, abdominales, dorsales, caudales. Los tres primeros elementos (cervicales) y la $10^{\text {a }}$ (supra-dorsal) muestran una estructura morfológica peculiar y adaptaciones locales, asociadas con la angulación del cuello y los músculos de la aleta dorsal, respectivamente. El tamaño vertebral disminuye desde elemento más anterior hacia atrás, con algunas variaciones locales en la zona dorsal. Los principales cambios están relacionados con la variación alométrica en la región neural. Los elementos caudales se caracterizan por una marcada disminución de tamaño, con los consiguientes cambios en la formas aloméricas de rotación de la abertura vertebral posterior. Esta trayectoria alométrica conduce a una flexión ventral natural de la cola, promoviendo su función prensil. Este estudio morfológico sugiere una interesante red estructural entre postura, locomoción y la anatomía vertebral junto a los principales cambios funcionales en la biomecánica de Hippocampus. La morfometría geométrica es bastante adecuada para los estudios con enfoques metaméricos, en términos de variación de serie y adaptaciones funcionales.

PALABRAS CLAVE: Metamerismo; Homología de serie; Análisis de forma; Caballo de mar; Esqueleto axial.

\section{REFERENCES}

Abouheif, E. \& Wray, GA. Evolution of Development. In: Encyclopedia of Life Science, London: Nature Publishing Group. Available: http://www.els.net, 2002.
Adams, D. C.; Rohlf, F. J. \& Slice, D. E. Geometric morphometrics: ten years of progress following the "revolution". Ital. J. Zool., 71(1):5-16, 2004. 
Ashley-Ross, M. A. Mechanical properties of the dorsal fin muscle of seahorse (Hippocampus) and pipefish (Syngnathus). J. Exp. Zool., 293(6):561-77, 2002.

Blake, R. W. On seahorse locomotion. J. Marine Biol. Assoc., 56:939-49, 1976.

Blake, R. W. Undulatory median fin propulsion of two teleosts with different modes of life. Can. J. Zool., 58: 2116-9, 1980.

Bookstein, F. L. Morphometric tools for landmark data: Geometry and biology. University Press, Cambridge, 1991.

Bookstein, F. L. Combining the tools of geometric morphometrics. In: Advances in morphometrics. Eds. Marcus, L.; Corti, M.; Loy, A.; Naylor, G. J. P. \& Slice, D. Plenum Press, New York, 1996.

Bookstein, F. L. Creases as local features of deformation grids. Med. Image Anal., 4:93-110, 2000.

Breder, C. M. \& Edgerton, H. E. An analysis of the locomotion. of the seahorse, Hippocampus, by means of high speed. cinematography. Ann. N. Y. Acad. Sci., 43:145-72, 1942.

Chatain, B. Abnormal swimbladder development and lordosis in sea bass (Dicentrarchus labrax) and sea bream (Sparus auratus). Aquaculture, 119:371-9, 1994.

Consi, T. R.; Seifert, P. A.; Triantafyllou, M. S. \& Edelman, E. R. The dorsal fin engine of the seahorse (Hippocampus sp.). J. Morphol., 248:80-97, 2001.

Corti, M. \& Rohlf, F. J. Use of two-block partial least-squares to study covariation in shape. Syst. Biol., 49:740-53, 2000.

Dawson, C. E. Indo-Pacific pipefishes (Red Sea to the Americas). Gulf Coast Research Laboratory. Ocean Springs, Mississippi, 1985.

Divanach, P.; Boglione, C.; Menu, B.; Koumoundouros, G.; Kentouri, M. \& Cataudella S. Abnormalities in finfish mariculture: an overview of the problem, causes and solutions. In: Seabass and Seabream culture: Problems and Prospects. Eds. Chatain, B.; Saroglia, M.; Sweetman, J. \& Lavens, P. European Aquaculture Society, Verona, 1996.

Divanach, P.; Papandroulakis, N.; Anastasiadis, P.; Koumoundouros, G. \& Kentouri, M. Effect of water currents on the development of skeletal deformities in sea bass (Dicentrarchus labrax L.) with functional swimbladder during postlarval and nursery phase, Aquaculture, 156(1-2):145-55, 1997.

Galis, F. Why Do Almost All Mammals Have Seven Cervical Vertebrae? Developmental Constrains, Hox Genes, and Cancer. J. Exp. Zool. (Mol. Dev. Evol.), 285:19-26, 1999.

Galis, F.; Van Alphen, J. J. M. \& Metz, J. A. J. Why five fingers? Evolutionary constrains on digit numbers. Trends Ecol. Evol., 16(11):637-46, 2001.

Gould, S. J. Allometry and size in ontogeny and phylogeny. Biol. Rev., 41:587-640, 1966.

Grassé, P. P. Traité de Zoologie. Agnathes et poissons, anatomie, éthologie, systématique. Tome XIII. Masson, Paris, 1958.

Hale, M. E. Mechanisms of bending and holding in seahorses and pipefishes (Teleostei: Syngnathidae). Am. Zool., 33:120A, 1993.

Hale, M. E. Functional morphology of ventral tail bending and prehensil abilities of the seahorse, Hippocampus kuda. J. Morphol., 227:51-65, 1996.

Kihara, M.; Ogata, S.; Kawano, N.; Kubota, I. \& Yamaguchi, R. Lordosis induction in juvenile red sea bream, Pagrus major, by high swimming activity. Aquaculture, 212:1489, 2002.

Klingenberg, C. P. Heterochrony and allometry: the analysis of evolutionary change in ontogeny. Biol. Rev. Camb. Philos. Soc., 73:79-123, 1998.

Klingenberg, C. P. Morphometrics and the role of the phenotype in studies of the evolution of developmental mechanisms. Gene, 287:3-10, 2002.

Koumoundouros, G.; Sfakianakis, D. G.; Divanach, P. \& Kentouri, M. Effect of temperature on swimming performance of sea bass juveniles. J. Fish Biol., 60:923-32, 2002.

Kranenbarg, S.; Waarsing, J. H.; Muller, M.; Weinans, H. \& Van Leeuwen, J. L. Lordotic vertebrae in sea bass (Dicentrarchus labrax L.) are adapted to increased loads. J. Biomech., 38:1239-46, 2005.

Lewis, E. B. A gene complex controlling segmentation in Drosophila. Nature, 276(5688):565-70, 1978. 
Lim, C. \& Lovell, R. T. Pathology of the vitamin c deficiency syndrome in channel catfish (Ictalurus punctatus). $J$. Nutrition, 108:1137-46, 1978.

Lindsey, C. C. Form, function, and locomotory habits in fish. In: Fish physiology, Eds. Hoar, W. S. \& Randall, D. J. Academic Press, New York, 1978.

Lourie, S. A.; Vincent, A. C. J. \& Hall, H. J. Seahorses: an identification guide to the world's species and their conservation. Project Seahorse, London, 1999.

Marcus, L. F.; Corti, M.; Loy, A.; Naylor, G. J. P. \& Slice, D. E. Advances in Morphometrics. Plenum Press, New York, 1996.

Mindell, D. P. \& Meyer, A. Homology evolving. Trends Ecol. Evol., 16(8):434-40, 2001.

Minelli, A.; Foddai, D.; Pereira, L. A. \& Lewis, J. G. E. The evolution of segmentation of centipede trunk and appendages. J. Zool. Syst. Evol. Research, 38:103-17, 2000.

Minelli, A. Limbs and tail as evolutionarily diverging duplicates of the main body axis. Evol. Dev., 2(3):157-65, 2000.

Minelli, A. L'omologia rivisitata. Systema Naturae, 4:209-53, 2002.

Minelli, A. \& Fusco, G. Evo-devo perspectives on segmentation: model organisms, and beyond. Trends Ecol. Evol., 19(8):423-9, 2004.

Mitteroecker, P.; Philipp Gunz, P. \& Bookstein, F. L. Heterochrony and geometric morphometrics: a comparison of cranial growth in Pan paniscus versus Pan troglodytes. Evol. Dev., 7:244-58, 2005.

Nelson, J. S. Fishes of the world. $3^{\text {rd }}$. Ed. John Wiley \& Sons, New York, 1994.

Nüsslein-Volhard, C. \& Weischaus, E. Mutations affecting segment number and polarity in Drosophila. Nature, 287(5785):795-801, 1980.

Owen, R. Lectures on the comparative anatomy and physiology of the invertebrate animals, delivered at the Royal College of Surgeons in 1843. Longman, Brown, Green and Longmans, London, 1843.

Parker, H. W. \& Bellairs, A. Gli Anfibi e i Rettili. La grande enciclopedia della natura. Garzanti, Milano, 1973.
Pepper, J. W. The evolution of evolvability in genetic linkage patterns. Biosystems, 69:115-26, 2003.

Podani, J. Syn-Tax 5.1: a new version for PC and Macintosh computers. Coenoses, 12:149-52, 1997.

Podani, J. Syn-Tax, Computer program for data analysis in ecology and systematics. Scientia Publishing, Budapest, 2000.

Rauther, M. Die Syngnathiden des Golfes von Neapel. Friedländer \& Sohn, Berlin, 1925.

Rohlf, F. J. Relative warp analysis and an example of its application to mosquito wings. In: Contributions to Morphometrics. Marcus, L. F.; Bello, E. \& GarciaValdecasas, A. Museo Nacional de Ciencias Naturales, Madrid, 1993.

Rohlf, F. J. tpsSpline 1.15. Department of Ecology and Evolution. State University of New York. Stony Brook, NY, 1997.

Rohlf, F. J. tpsRegr 1.20. Department of Ecology and Evolution. State University of New York. Stony Brook, NY, 1998a.

Rohlf, F. J. tpsRelw 1.18. Department of Ecology and Evolution. State University of New York. Stony Brook, NY, 1998b.

Rohlf, F. J. tpsSmall 1.19. Department of Ecology and Evolution. State University of New York. Stony Brook, NY, 1998c.

Rohlf, F. J. tpsPLS 1.12. Department of Ecology and Evolution. State University of New York. Stony Brook, NY, 2002.

Rohlf, F. J. \& Marcus, L. F. A Revolution in Morphometrics. Trends Ecol. Evol., 8:129-32, 1993.

Schlosser, G. Modularity and the units of evolution. Theory Biosci., 121:1-80, 2002.

Sfakianakis, D. G.; Koumoundouros, G.; Anezaki, L.; Divanach, P. \& Kentouri, M. Development of a saddleback-like syndrome in reared white seabream Diplodus sargus (Linnaeus, 1758). Aquaculture, 217:673-6, 2003.

Shea, B. T. Developmental perspective on size change and allometry in evolution. Evol. Anthropol., 1:125-34, 1992. 
BRUNER, E. \& BARTOLINO, V. Morphological variation in the seahorse vertebral system. Int. J. Morphol., 26(2):247-262, 2008

Slice, D. Morpheus. Department of Ecology and Evolution, State University of New York. Stony Brook, NY, 2000.

Staton, J. L. Homology in Character Evolution. In: Encyclopedia of Life Science, London: Nature Publishing Group. Available: http://www.els.net, 2000.

Videler, J. J. Fish swimming. Chapman \& Hall, London, 1993.

Vincent, A. C. J. Seahorses exhibit conventional sex roles in mating competition, despite male pregnancy. Behaviour, 128(1-2):135-51, 1994.
Correspondence to:

Valerio Bartolino

Department of Animal and Human Biology

University of Rome La Sapienza

Viale dell'Università 32, 00185, Roma

ITALY

Phone. 06.4991.4763

Email: valerio.bartolino@uniroma1.it

Received: 08-12-2007

Accepted: 07-02-2008 